\title{
Editorial
}

\section{Hydrogen Sulfide: Biogenesis, Physiology, and Pathology}

\author{
Jin-Song Bian, ${ }^{1}$ Kenneth R. Olson, ${ }^{2}$ and Yi-Chun $\mathrm{Zhu}^{3}$ \\ ${ }^{1}$ Department of Pharmacology, Yong Loo Lin School of Medicine, National University of Singapore, Singapore 117597 \\ ${ }^{2}$ Department of Physiology, University of Notre Dame, 1234 Notre Dame Avenue, South Bend, IN 46617, USA \\ ${ }^{3}$ Department of Physiology and Pathophysiology, Fudan University Shanghai Medical College, 138 Yi Xue Yuan Road, \\ Shanghai 200032, China
}

Correspondence should be addressed to Jin-Song Bian; phcbjs@nus.edu.sg

Received 28 March 2016; Accepted 29 March 2016

Copyright (c) 2016 Jin-Song Bian et al. This is an open access article distributed under the Creative Commons Attribution License, which permits unrestricted use, distribution, and reproduction in any medium, provided the original work is properly cited.

The seminal studies by Kimura's group in the late 1990s [1,2] ushered in a new era of biological signaling mediated by hydrogen sulfide $\left(\mathrm{H}_{2} \mathrm{~S}\right) . \mathrm{H}_{2} \mathrm{~S}$ has been described as the third "gasotransmitter" along with nitric oxide (NO) and carbon monoxide (CO; [3]). While none of these molecules actually signal as a gas, their hydrophilicity and lipophilicity enable them to readily traverse intracellular compartments where they serve in a variety of autocrine and paracrine signals capacities.

Of the three, however, $\mathrm{H}_{2} \mathrm{~S}$ is arguably the most chemically reactive and biologically diverse. As a weak acid, $\mathrm{H}_{2} \mathrm{~S}$ exists as the dissolved gas and hydrosulfide anion $\left(\mathrm{HS}^{-}\right)$in nearly equal proportions in the circumneutral intracellular milieu. $\mathrm{H}_{2} \mathrm{~S}$ is readily oxidized to per- and polysulfides $\left(\mathrm{H}_{2} \mathrm{~S}_{n}\right)$ forming a highly reactive group of molecules (reactive sulfide species, RSS) that readily form reversible covalent bonds, coordinate with metal ligands, and participate in a variety of redox reactions $[4,5] . \mathrm{H}_{2} \mathrm{~S}$ was key in the origin of life [6] and it remains as the only inorganic substrate used by eukaryotic cells to generate ATP [7]. $\mathrm{H}_{2} \mathrm{~S}$ mediates many physiological functions in various biological systems including cytoprotection, neuromodulation, ischemic responses, and oxygen sensing. Exogenous application of $\mathrm{H}_{2} \mathrm{~S}$ may protect cell function against ischemic and oxidant injuries. Despite the fact that the multiple roles of $\mathrm{H}_{2} \mathrm{~S}$ in biology have been intensely discussed over the last twenty years, many questions remain to be resolved. The eclectic nature of $\mathrm{H}_{2} \mathrm{~S}$ is featured in this special issue as a collection of original articles and reviews that examine a variety of the physiological functions of $\mathrm{H}_{2} \mathrm{~S}$ as well as its therapeutic attributes.
The role of $\mathrm{H}_{2} \mathrm{~S}$ in oxidative stress has been one of the main focuses over the last two decades. The review by Xie et al. focuses on the new understanding and mechanisms of the antioxidant effects of $\mathrm{H}_{2} \mathrm{~S}$ based on recent reports. As a poor reducing agent, $\mathrm{H}_{2} \mathrm{~S}$ may react directly with and quench superoxide, peroxynitrite, and other ROS. However, the direct antioxidant effect may not be its main function. $\mathrm{H}_{2} \mathrm{~S}$ can scavenge free radicals via activation of both nonenzymatic (e.g., glutathione and thioredoxin) and enzymatic (e.g., superoxide dismutase, catalase, and glutathione peroxidase) antioxidants. Apart from stimulation of cellular antioxidant defenses, $\mathrm{H}_{2} \mathrm{~S}$ may also inhibit the overproduction of ROS via modification of the structure of p66Shc at cysteine-59. This subsequently inhibits mitochondrial ROS generation in the mitochondria. Thus, this review provides new insights to better understand the important role of the $\mathrm{H}_{2} \mathrm{~S}$ in oxidative stress and the related diseases.

Being gaseous molecules and mediators, both $\mathrm{H}_{2} \mathrm{~S}$ and NO play important roles in various biological systems. While the individual signaling mechanisms mediated by $\mathrm{H}_{2} \mathrm{~S}$ and $\mathrm{NO}$ in mammals are extensively studied, our understanding about the potential relationship between these two gasotransmitters is woefully incomplete. Nagpure and Bian reviewed recent research progress in the interactions between these two gaseous mediators. $\mathrm{H}_{2} \mathrm{~S}$ may reduce oxidized $\mathrm{NO}$ leading to the formation of $\mathrm{HSNO}$ as an intermediate. Further reduction and direct displacement of $\mathrm{HSNO}$ by $\mathrm{H}_{2} \mathrm{~S}$ result in the formation of another intermediate product, nitroxyl (HNO). Interestingly, $\mathrm{HNO}$ produces chemical and physiological functions different from $\mathrm{NO}$ and $\mathrm{H}_{2} \mathrm{~S}$. The role of this 
interaction in heart and vascular physiology and pathology is also summarized in this review.

In the original article by $\mathrm{D}$. Wu et al., the authors studied the interaction between $\mathrm{H}_{2} \mathrm{~S}$ and $\mathrm{NO}$ in vasculature using a novel $\mathrm{H}_{2} \mathrm{~S}$ and $\mathrm{NO}$ conjugated donor, ZYZ-803. The authors found that, by releasing $\mathrm{H}_{2} \mathrm{~S}$ and $\mathrm{NO}, \mathrm{ZYZ}$ 803 time- and dose-dependently relaxed rat aortic rings. Mechanistic studies revealed that the effect of ZYZ-803 was mediated by cGMP. Interestingly, suppression of either $\mathrm{H}_{2} \mathrm{~S}$ or $\mathrm{NO}$ generation with their respective inhibitors abolished the vasorelaxant effect of ZYZ-803. These interesting data suggest that $\mathrm{H}_{2} \mathrm{~S}$ and $\mathrm{NO}$ generated from $\mathrm{ZYZ}-803$ can cooperatively regulate vascular tone.

In the original article by P. Huang et al., the authors investigated whether $\mathrm{H}_{2} \mathrm{~S}$ can prevent high-salt diet-induced renal injury. Dahl rats on a high-salt diet for 8 weeks developed hypertension and kidney injury with excessive oxidative stress and an obvious reduction of endogenous $\mathrm{H}_{2} \mathrm{~S}$. Exogenous application of $\mathrm{H}_{2} \mathrm{~S}$, however, decreased blood pressure and improved renal function. The authors believe that the beneficial effects of $\mathrm{H}_{2} \mathrm{~S}$ resulted from Keap1/Nrf2 disassociation.

Sulfur dioxide $\left(\mathrm{SO}_{2}\right)$ has also long been thought to be a toxic gas. A group of scientists in China recently reported that this gas can be produced endogenously. In the review article by Y. Huang et al., the authors summarized the physiological and pathological functions of $\mathrm{SO}_{2}$ in the cardiovascular system. These include regulation of vascular tone and heart contractility and its effects on disease status like systemic and pulmonary hypertension, atherosclerosis, and ischemic diseases. Based on these effects, they propose that endogenous $\mathrm{SO}_{2}$ may be a potential therapeutic target for cardiovascular diseases.

In the original article by N. Li et al., the authors examined the effect of $\mathrm{H}_{2} \mathrm{~S}$ on protein expression of various $\mathrm{H}_{2} \mathrm{~S}$ generating enzymes in both ischemic heart tissue and cultured cardiomyocytes during hypoxia. They found that NaHS treatment upregulated protein expression of various enzymes with different patterns in the two pathological situations. The authors believe that CSE may serve as the most important enzyme to regulate $\mathrm{H}_{2} \mathrm{~S}$ production in myocardium. This is because when CSE was deleted, the compensatory expressions of CBS and 3-MST were not enough to rescue $\mathrm{H}_{2} \mathrm{~S}$ levels and protect the heart. These interesting data suggest that exogenous $\mathrm{H}_{2} \mathrm{~S}$ may alter the production of endogenous $\mathrm{H}_{2} \mathrm{~S}$ and therefore protect the heart with a new mechanism.

Respiratory and gastrointestinal epithelia are directly exposed to environmental- or bacterial-derived $\mathrm{H}_{2} \mathrm{~S}$ which can raise the $\mathrm{H}_{2} \mathrm{~S}$ concentration in these tissues. E. Pouokam and $\mathrm{M}$. Althaus discussed in their review article how epithelial cells quickly process and maintain $\mathrm{H}_{2} \mathrm{~S}$ level to prevent excessive increases. They proposed a new concept that electrolyte and liquid transport machinery inside epithelia may serve as a fortress against potentially harmful higher level $\mathrm{H}_{2} \mathrm{~S}$. In this interesting review article, reactions to exposed $\mathrm{H}_{2} \mathrm{~S}$ and potential physiological and pathophysiological implications were also discussed.

Vascular calcification (VC) is a refractory component of many cardiovascular diseases and is associated with hypertension (HT) and endoplasmic reticulum stress (ERS). In this original research article, R. Yang et al. induced VC and $\mathrm{HT}$ in rats with vitamin $\mathrm{D}_{3}$ and observed that daily i.p. injection of $\mathrm{H}_{2} \mathrm{~S}$ (as $\mathrm{NaSH}$ ) over 28 days prevented VC, HT, and conversion of vascular smooth muscle cells from a contractile to an osteoblast-like phenotype common in VC. $\mathrm{H}_{2} \mathrm{~S}$ also prevented VC-induced downregulation of cystathionine $\gamma$-lyase and the authors presented evidence that suggested $\mathrm{H}_{2} \mathrm{~S}$ also ameliorated ERS. This article adds yet another piece to the ever growing body of evidence that $\mathrm{H}_{2} \mathrm{~S}$ is a general cardiovascular protectant.

Unfortunately, this issue can only touch on a few select aspects of $\mathrm{H}_{2} \mathrm{~S}$ biology. However, we hope this broadspectrum, albeit limited, approach serves to illustrate the myriad of physiological processes potentially influenced by $\mathrm{H}_{2} \mathrm{~S}$ and entice new investigators into this exciting field.

\section{Jin-Song Bian \\ Kenneth R. Olson Yi-Chun Zhu}

\section{References}

[1] K. Abe and H. Kimura, "The possible role of hydrogen sulfide as an endogenous neuromodulator," The Journal of Neuroscience, vol. 16, no. 3, pp. 1066-1071, 1996.

[2] R. Hosoki, N. Matsuki, and H. Kimura, "The possible role of hydrogen sulfide as an endogenous smooth muscle relaxant in synergy with nitric oxide," Biochemical and Biophysical Research Communications, vol. 237, no. 3, pp. 527-531, 1997.

[3] R. Wang, "Two's company, three's a crowd: can $\mathrm{H}_{2} \mathrm{~S}$ be the third endogenous gaseous transmitter?" The FASEB Journal, vol. 16, no. 13, pp. 1792-1798, 2002.

[4] M. R. Filipovic, "Persulfidation (S-sulfhydration) and $\mathrm{H}_{2} \mathrm{~S}$," Handbook of Experimental Pharmacology, vol. 230, pp. 29-59, 2015.

[5] P. Nagy, "Mechanistic chemical perspective of hydrogen sulfide signaling," Methods in Enzymology, vol. 554, pp. 3-29, 2015.

[6] K. R. Olson and K. D. Straub, "The role of hydrogen sulfide in evolution and the evolution of hydrogen sulfide in metabolism and signaling," Physiology, vol. 31, no. 1, pp. 60-72, 2015.

[7] M. Goubern, M. Andriamihaja, T. Nübel, F. Blachier, and F. Bouillaud, "Sulfide, the first inorganic substrate for human cells," The FASEB Journal, vol. 21, no. 8, pp. 1699-1706, 2007. 


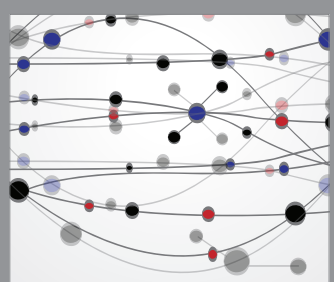

The Scientific World Journal
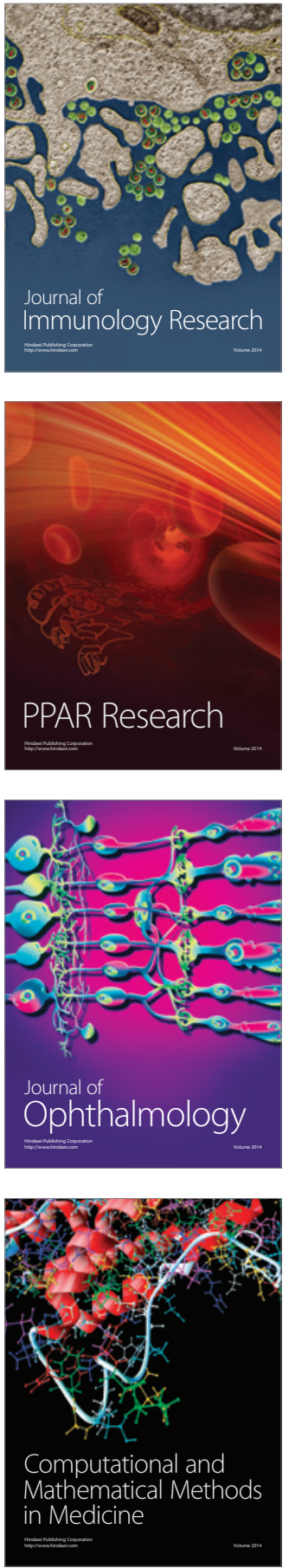

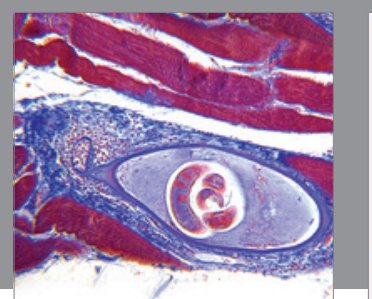

Gastroenterology Research and Practice

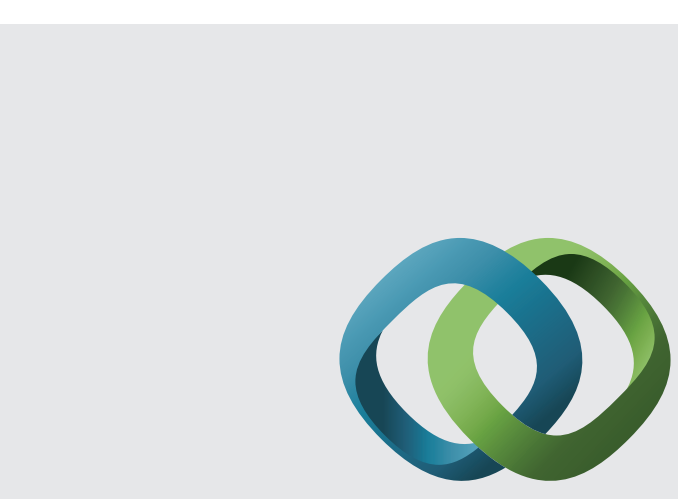

\section{Hindawi}

Submit your manuscripts at

http://www.hindawi.com
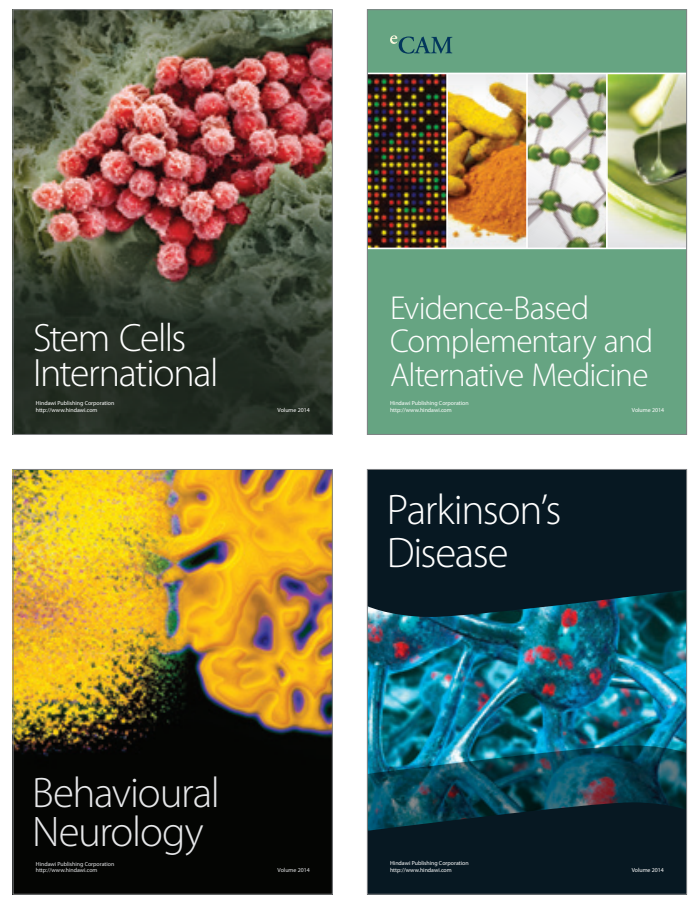
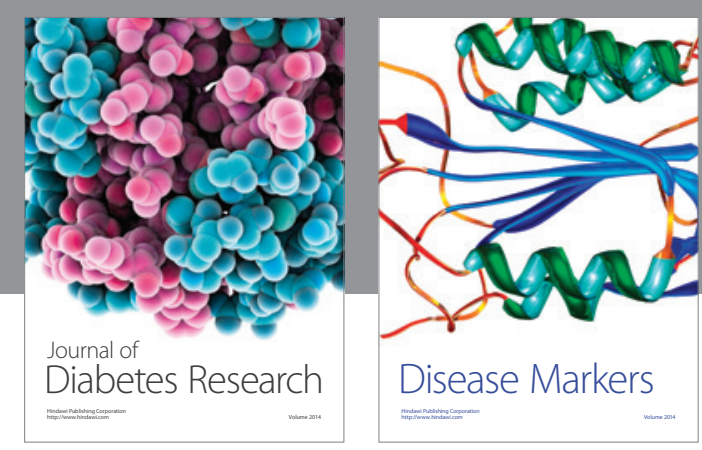

Disease Markers
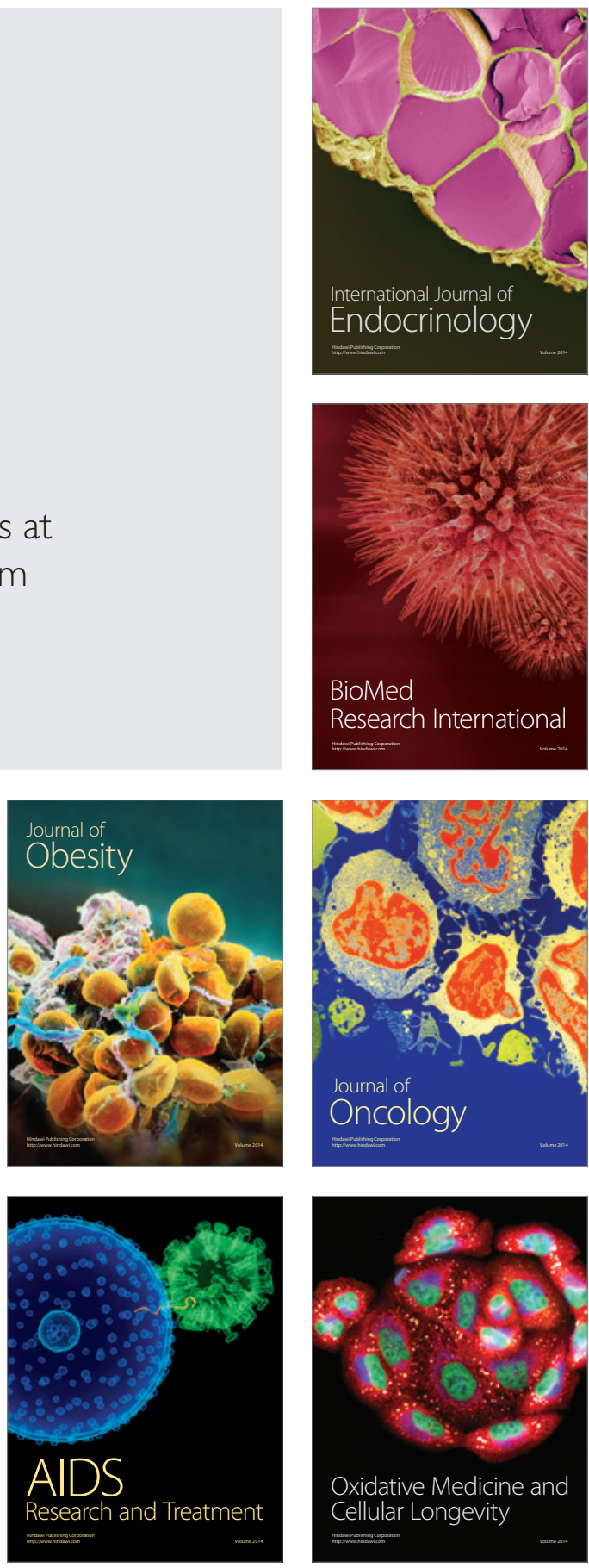